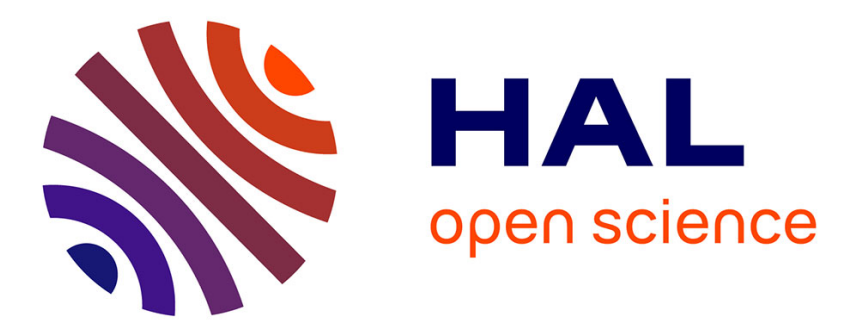

\title{
Genomic predictors of response to doxorubicin versus docetaxel in primary breast cancer
}

M. Martin, A. Romero, M. C. U. Cheang, J. A. López García-Asenjo, J. A. García-Saenz, B. Oliva, J. M. Román, X. He, A. Casado, J. Torre, et al.

\section{- To cite this version:}

M. Martin, A. Romero, M. C. U. Cheang, J. A. López García-Asenjo, J. A. García-Saenz, et al.. Genomic predictors of response to doxorubicin versus docetaxel in primary breast cancer. Breast Cancer Research and Treatment, 2011, 128 (1), pp.127-136. 10.1007/s10549-011-1461-y . hal-00629079

\section{HAL Id: hal-00629079 https://hal.science/hal-00629079}

Submitted on 5 Oct 2011

HAL is a multi-disciplinary open access archive for the deposit and dissemination of scientific research documents, whether they are published or not. The documents may come from teaching and research institutions in France or abroad, or from public or private research centers.
L'archive ouverte pluridisciplinaire $\mathbf{H A L}$, est destinée au dépôt et à la diffusion de documents scientifiques de niveau recherche, publiés ou non, émanant des établissements d'enseignement et de recherche français ou étrangers, des laboratoires publics ou privés. 


\section{Genomic predictors of response to doxorubicin versus docetaxel in primary breast cancer}

M. Martin, M.D., Ph.D, ${ }^{1}$ A. Romero, M.D., Ph.D., ${ }^{2}$ MCU. Cheang, Ph.D., ${ }^{3}$ J.A. López GarcíaAsenjo, M.D., Ph.D., ${ }^{2}$ J.A. García-Saenz, M.D., Ph.D., ${ }^{2}$ B. Oliva, Ph.D., ${ }^{4}$ J.M. Román, M.D., Ph.D., ${ }^{2}$ X. He, Ph.D., ${ }^{3}$ A. Casado, M.D., Ph.D., ${ }^{2}$ J. de la Torre ${ }^{2}$, R.N., ${ }^{2}$ V. Furio ${ }^{2}$, J. Puente, M.D. Ph.D. ${ }^{2}$, T. Caldés, M.D., Ph.D., ${ }^{2}$ J.A. Vidart, M.D., Sara Lopez-Tarruella ${ }^{1}$, Ph.D., ${ }^{2}$ E. Diaz-Rubio, M.D., Ph.D., ${ }^{2}$ and CM Perou, Ph.D. ${ }^{3}$

${ }^{1}$ Hospital General Universitario Gregorio Marañon, Madrid, Spain

${ }^{2}$ Hospital Clinico San Carlos, Madrid, Spain

${ }^{3}$ Lineberger Comprehensive Cancer Center, University of North Carolina, Chapel Hill, NC, USA

${ }^{4}$ Instituto Carlos III, Madrid, Spain

Corresponding author:

Miguel Martin. Servicio de Oncología Médica. Hospital Universitario Gregorio Marañón. Universidad Complutense. c/Dr Esquerdo 46. 28007 Madrid. Spain.

mmartin.martin@salud.madrid.org

mmartin@geicam.org

Phone: $+34-915868115$

Fax: $+34-915737985$

Acknowledgements/Funding

This work was supported by grants from Fondo de Investigaciones Sanitarias (FIS PI07/0316), Red Temática de Investigación Cooperativa en Cáncer (RD06/0020/0021), Instituto de Salud Carlos III, Spanish Ministry of Science and Innovation; SEOM (Spanish Society for Medical Oncology); the NCI Breast SPORE program to UNC-CH (P50-CA58223-09A1); the Breast Cancer Research Foundation; and the V Foundation for Cancer Research. MCU Cheang is supported by Terry Fox Foundation Postdoctoral Fellowship. 


\section{ABSTRACT}

Purpose

Taxanes and anthracyclines improve the outcome of early breast cancer, although the benefit is limited to a small proportion of patients and are toxic. We prospectively looked for predictors of response to these drugs.

Experimental design

Four cycles of doxorubicin $\left(75 \mathrm{mg} / \mathrm{m}^{2}\right)$ or docetaxel $\left(100 \mathrm{mg} / \mathrm{m}^{2}\right)$ were compared as presurgical chemotherapy for breast cancer. Biomarkers were determined by immunohistochemistry and fluorescent in-situ hybridization using prechemotherapy core biopsies. Tumors were also classified into one of the molecular intrinsic subtypes using an immunohistochemical panel of 5 biomarkers and genomic profiles. Single genes and intrinsic subtypes were correlated with response to doxorubicin versus docetaxel .

Results

Among the 204 evaluable patients, significant predictors of sensitivity in multivariate analysis were low topo2a expression and ER-negative status for doxorubicin and small tumor size and ER-negative status for docetaxel. Predictors of resistance in multivariate analysis were triple-negative status (ER/PgR/HER2 negative by IHC/FISH) for doxorubicin, and high TNM stage for docetaxel. Triple-negative tumors were associated with topo2a overexpression more than the other subtypes. In 94 patients with gene expression profiles, docetaxel was superior to doxorubicin in the basal-like subtype (good pathological response rate PCR+class I- of $56 \%$ vs. $0 \%$; $p=0.034$ ); no significant differences were observed in the other subtypes when comparing these two drugs.

Conclusions

Low topo2a expression and ER-negative status were predictors of response to doxorubicin, while small tumor size and ER-negative status predicted response to docetaxel. Docetaxel was superior to doxorubicin in triple-negative/basal-like tumors, while no significant differences were seen in the remaining intrinsic subtypes. 


\section{INTRODUCTION}

The initial trials of adjuvant chemotherapy (CMF-like regimens) showed that these regimens could improve the outcomes of operable breast cancer patients [1]. Later, anthracycline combinations were found to be slightly but significantly more effective than the CMF regimen [2]. More recently, several adjuvant phase III trials have shown that taxane regimens further reduce the likelihood of recurrence and death, compared to anthracycline-containing combinations [3-10], but the absolute benefit was again small, and some trials were unable to show any advantage for the taxane arm $[11,12]$. Taxanes and anthracyclines can induce some acute and chronic toxicities of considerable clinical concern. Hence there is a pressing need to identify predictors for anthracycline and taxane response in breast cancer treatment.

The aforementioned adjuvant trials were conducted using unselected populations of breast cancer patients. Genomic studies performed in the early 2000s have revealed that breast cancer is a molecularly heterogeneous disease consisting of at least 4-5 different tumor subtypes [13-16]. In neoadjuvant trials using combinations of anthracycline and taxane, the sensitivity of the different molecular subtypes to chemotherapy varies; the basal-like and Her2-enriched subtypes showing the best response $[17,18]$. However, the relative contributions of each of these two classes of agents to response is still unknown.

To identify predictors of response, we performed this comparative, randomized neoadjuvant study comparing single agent docetaxel versus single agent doxorubicin in patients with locally advanced breast cancer. 


\section{PATIENTS AND METHODS}

Women eligible were aged between 18 and 79 years with clinical stage IIB, IIIA or IIIB breast cancer not amenable to breast preserving surgery. The study was approved by the institutional review board of the institutions (identifier code: NCT 00123929). All patients signed an informed consent form before being enrolled in the trial. A complete staging workup, including bilateral mammography and MRI, sonography of the affected breast, body CT scan, and bone scan, was carried-out prior to recruitment into the study.

\section{Study Objectives}

The primary study goal was to identify differential molecular/genomic predictors of response and resistance to single agents docetaxel vs doxorubicin.

\section{Study procedures}

Core biopsies of the tumor were obtained following the patient's informed consent for participation in the trial. Eligible patients were then randomly assigned to receive 4 cycles of either doxorubicin ( $75 \mathrm{mg} / \mathrm{m}^{2}$ body-surface area) or docetaxel (100 mg/m² body-surface area) every 3 weeks followed by surgery. After surgery, patient treatment assignment was crossed-over to receive 4 cycles of the opposite drug, plus radiation therapy. Patients whose tumors were positive for hormone receptors received tamoxifen, or aromatase inhibitors, or a sequence of both for at least 5 years. From May 2005 onwards, patients with her2amplified tumors received trastuzumab after surgery.

\section{Evaluation of response}

Clinical response was evaluated according to RECIST criteria comparing pre and postchemotherapy MRI breast assessments.

Pathological response was evaluated in the surgery specimen (either lumpectomy or mastectomy; both with additional axillary clearance) according to the residual cancer burden (RCB) classification of Symmans et al [19]. Patients with PCR and class I were considered as having a good pathological response (good PathResp) since both have an equivalent good prognosis, while those patients with class III were considered as resistant to therapy. This classification also provides a continuous variable (residual cancer burden -RCB-) which measures the amount of residual tumor burden, which could provide additional information. 


\section{Molecular and genomic studies}

IHC and FISH techniques

Paraffin-embedded tumor samples from core biopsies were evaluated by $\mathrm{IHC}$ analysis for p27 protein (mouse monoclonal antibody NCL-p27, Clone 1B4, 1:30 Leica Microsystems); topoisomerase Ila-topo2a- mouse monoclonal antibody NCL-Clone 3F6, 1:40 Leica Microsystems); BCL-2 (mouse monoclonal anti-human BCL-2 Oncoprotein, Clone 124, 1:100. Dako Cytomation), tau protein (Polyclonal Rabbit Anti-Human Tau dilution 1:200), estrogen receptor-ER (Dako Cytomation Clone 1D5, 1:35), progesterone receptor-PR (Dako Cytomation, Clone PgR 636, 1:50), epidermal growth factor receptor (EGFR, clone EGFRr.25, 1:50. Leica Microsystems), cytokeratins 5/6 (CK 5/6, clone D5/16B4, prediluted, Master Diagnostica) and Ki67 (Dako Cytomation, Clone MIB-1, 1:75). After incubation with the primary antibodies, the Bond Polymer Refine Detection with the Vision Biosystems Bondmax for immunostaining was applied.

Tau protein positivity was defined as $\geq 20 \%$ of stained cells, since the staining in our normal control breast tissue was always below that figure. The same cut-off point was used for Ki67. Since there is no standard cut-off for topoisomerase II alpha positivity, both means $(20 \%$ of stained cells, pre-specified cut-off point in the protocol) and median values (10\% of stained cells) were used for repeated analysis. Positivity for p27, BCL-2, EGFR and CK 5/6 was defined as any degree of positive staining. The cut-off value for ER and PR positivity was established at $\geq 10 \%$ of stained cells in the original protocol but, again, the univariate and multivariate analysis were also repeated using a cut-off point of $1 \%$.

HER2 and TOP2A gene amplification were evaluated by fluorescence in situ hybridization (FISH) (HER2 FISH 30-161060 Path Vysion HER-2 DNA and the TOPII $\alpha$ FISH 32-190095 Vysis LSI TOPII $\alpha$ respectively) and to centromere 17 according to manufacturer's instructions. Tumors were considered positive for HER2 if amplification ratio more than 2.2 and for TOP2A if amplification ratio more than 2 . The cut off for the deletion positivity was established as a TOP2A genes to chromosome 17 ratio of less than 0.5 . All the cut-off points were predefined before the correlations with response were performed. In all the determinations, the pathologist was blinded from patient's outcome and treatments.

Tumors were classified into molecular intrinsic subtypes based either on IHC/FISH parameters or using gene expression profiles [20-22]. The first method was based on an immunopanel of 4 biomarkers previously described by Hugh et al [22] that includes 4 subtypes (luminal A and B, HER2, and triple negative):

-luminal A: ER ${ }^{+}$and/or $\mathrm{PR}^{+}, \mathrm{HER}^{-}$(FISH), KI67 $\leq 13 \%$ 
-luminal B: ER ${ }^{+}$and/or $\mathrm{PR}^{+}$, and either $\mathrm{HER}^{+}(\mathrm{FISH})$ or $\mathrm{KI} 67>14 \%$

-HER2: $\mathrm{ER}^{-}$and $\mathrm{PR}^{-}, \mathrm{HER}^{+}(\mathrm{FISH})$

-Triple-negative: $\mathrm{ER}^{-}, \mathrm{PR}^{-}$and $\mathrm{HER} 2^{-}$(FISH)

The second approach was based on the "gold-standard" of gene expression profiles as assayed by DNA microarrays. The background subtracted Lowess normalized log2 ratio of Cy3 and Cy5 intensity values were retrieved and used for all subsequent analyses. The primary microarray data presented in this study is available in the GEO under accession number GSE21997. Tumors were classified into an intrinsic subtype (Luminal A, Luminal B, Her2-enriched, Basal-like and Normal-like) using the PAM50 50-gene assays a as described in Parker et al [19]. In addition, a recent identified subtype, namely Claudin-low, was also scored for using a centroid based predictor for this subtype [21]; in total, these two predictors (i.e. PAM50 and Claudin-low versus not, result in a 6 subtype classification system that is Luminal A, Luminal B, Basal-like, HER2-enriched, Claudin-low, and Normal-like).

The second method was based on Agilent Human oligonucleotide microarrays. 94 fresh frozen core biopsies were assayed on customized 44,000 feature Agilent Human oligonucleotide microarrays. Total RNA purification and microarrays hybridization were done as previously described in Parker et al [20]. The primary microarray data presented in this study is available in the GEO under accession number GSE21997. Tumors were classified into an intrinsic subtype using the PAM50 50-gene assays [19]. In addition, a recent identified subtype, namely Claudin-low, was also scored for using a centroid based predictor for this subtype [21]; in total, these two predictors result in a 6 subtype classification system that is Luminal A, Luminal B, Basal-like, HER2-enriched, Claudin-low, and Normal-like.

\section{Statistical Analysis}

An empirical sample size of 100 evaluable patients in each treatment arm was established based on an assumption that if powerful predictors to response for these two drugs did exist, this sample size would be sufficient to detect a difference, and large enough to rule out the weak association of less important molecular markers.

The significant asassociation between categorical variables was tested by either chi-squared or Fisher exact test when appropriate. The association between the RBC index scores and other clinicopathological variables was assessed by U Mann-Whitney/t-student test. Variables with clear or borderline statistical significance response to treatment in univariate 
analysis were included in a multivariable step-wise logistic regression model. Likelihood ratio test were used if the variables add significance to the predictive model.

Finally, a logistic regression analysis was performed for PathResp involving the overall population (204 patients). The covariates used in the analysis were those previously described as well as the presence/absence of interaction between the molecular predictors of response to either drug (top2A and ER expression) and the chemotherapy treatment. Adjustments were made for multiple comparisons. The statistical analysis was performed using SPSS 15.0/strata 10 package. All tests were two-tailed and $p$-values $<0.05$ were considered significant.

\section{Results}

226 patients were initially registered; 211 were eligible and randomized to docetaxel $(n=104)$ or doxorubicin ( $n=107) ; 204$ patients (100 in the docetaxel arm and 104 in the doxorubicin arm) were fully evaluable for the statistical analyses of biomarker predictors and pathological response (see Apendix 1 Consort diagram). The clinical and demographic characteristics of the patients are shown in Table 1. Genomic profiling was successfully performed in 94 patients ( $46 \%$ of total), whose characteristics were not significantly different from the overall sample (data not shown).

\section{Anti-tumor activity}

Clinical objective response rates (RECIST criteria) were $67 \%$ for doxorubicin and $77 \%$ for docetaxel $(p=0.12)$. The rates of good PathResp were $19 \%$ in the doxorubicin arm and $20 \%$ in the docetaxel arm $(p=0.89)$.

\section{A. Prediction of anti-tumor activity: single biomarker model}

\section{A.1. Prediction of chemo-sensitivity (good PathResp; Symmans class 0+l)}

Table 2 summarized the results of univariate analysis by treatment arm. The multivariable logistic regression analysis (Table 3) showed that topo2a and ER expression were the two independent significant molecular markers to response to doxorubicin. ER status provided significant additional information over topo2a (Wald likelihood-ratio test; $p=0.0105$ ). Tumor size (Tsize) and ER status were the two independent predictors to response to docetaxel. Again, ER status provided additional information over Tsize (Wald likelihood-ratio test; $\mathrm{p}=0.0004)$. 
The results were remarkably similar when a cut point of 10\% (topo2a) and 1\% (hormone receptors status) were used to define positivity (data not shown).

To investigate if there was an interaction between the significant variables and treatments, an additional multivariable logistic model was built by combining the doxorubicin-treated and docetaxel-treated patients. The interaction terms, topo2a expression/treatment and ER status/treatment interactions were included as covariates. In this multivariable model, there was a significant interaction between topo2a expression and treatments $(p=0.048)$, but there was no significant interaction between ER status and treatments (on line only, Table $3 e$ ). Figure 1 shows the correlation between topo2a protein expression and good PathRes in both arms.

\section{A.2. Prediction of chemo-resistance (poor PathResp, RCB class III)}

Among patients treated with doxorubicin, no significant variables predicting chemoresistance (as defined as being RCB class III) were found (Table 43, on line only). Tumor size and tumor stage were associated with a significantly higher Symmans class III in univariate analysis on patients treated with docetaxel. In multivariable logistic regression analysis, tumor stage was the only independent predictor of chemo-resistance to docetaxel. The adjusted odds ratios for poor PathResp to docetaxel for Stage IIIA and IIIB tumors relative to Stage II tumors were $4.77(95 \% \mathrm{Cl}: 1.33-17.11 ; \mathrm{p}=0.016)$ and $8.76(95 \% \mathrm{Cl}$ : 2.53-30.353; $\mathrm{p}=0.001$ ), respectively.

\section{B. Predicting anti-tumor activity by intrinsic breast cancer subtypes}

\section{B.1. IHC-FISH-based classification}

The differential response of intrinsic tumor subtypes to doxorubicin versus docetaxel is shown in Table 4. No selective differences in activity between doxorubicin and docetaxel were seen in the luminal and her2 subtypes. However, triple negative patients treated with doxorubicin had a significantly higher mean RCB (3.255 vs. 2.238; $\mathrm{p}=0.025)$ and a significantly higher proportion of poor PathResp ( $70 \%$ vs. 32\%, $p=0.010)$ than those treated with docetaxel. The good PathResp rate was also numerically superior with docetaxel $(10 \%$ vs. $29 \%)$, although this difference did not reach statistical significance $(\mathrm{p}=0.160)$.

In view of these findings, we included a binary variable defined as triple-negative vs. not to the multivariable models predicting good and bad PathRes respectively. In the model predicting good PathResp, triple negative phenotype was not an independent predictor of response to either docetaxel or doxorubicin. On the other hand, in the model predicting bad PathResp, triple-negative phenotype was the only independent predictor of poor response to 
doxorubicin. Triple negative patients treated with doxorubicin had an odds ratio for bad PathResp of $4.42(95 \% \mathrm{Cl} 1.53-12.73, \mathrm{p}=0.006)$ with respect to non-triple negative patients treated.

\section{B.2. Gene expression profiles-based classification of molecular intrinsic subtypes}

A subset of evaluable patients (94/204) were also expression profiled on 44,000 feature full genome Agilent microarrays. Basal-like breast cancer was the only subtype that showed selective benefit for docetaxel over doxorubicin in terms of good PathRes (56\% vs $0 \%, p=$ 0.029), and mean RCB (1.626 vs 3.245, $\mathrm{p}=0.039$ ) (Table 5).

\section{Correlation between variables}

Figure 2 shows the relationship between topo2a protein overexpression and intrinsic subtype based on IHC/FISH. The rate of topo2a protein overexpression was different among subtypes $(p=0.006)$, with the triple negative subset showing the higher rate $(50 \%)$.

\section{DISCUSSION}

In our trial, doxorubicin and docetaxel had similar antitumor activity in primary breast cancer. The few neoadjuvant studies conducted to-date with single agent doxorubicin or docetaxel reported a very similar activity [23-25]. In our trial, ER negative status was a strong but unspecific predictor of sensitivy to either docetaxel and doxorubicine. Low topo2a protein expression was an independent predictor of response to doxorubicin, while small tumor size predicts the response to docetaxel. On the other hand, tumors with triple negative status (by IHC/FISH) and basal-like subtype tumors defined by gene expression profiles were sensitive to docetaxel but appears to be resistant to doxorubicin. There was no significant differences among the other genomic subtypes.

With respect to doxorubicin, several studies have tried to identify single gene/protein biomarkers to predict anti-tumor activity. Both HER2 and TOPA2 gene status/protein expression have been reported as predictors of response in the adjuvant setting [26,27]. A pooled analysis of trials published in the literature [28] has suggested that $H E R 2$ overexpression/amplification predicts response to adjuvant anthracycline combinations. The final conclusions remains debatable as there might be a selection bias in these publications. In patients with advanced tumors, the results of the trials evaluating relationships between HER2 and response to doxorubicin are contradictory [29-34], but most studies had been retrospective and too underpowered to show clinically relevant correlations. Our study did not observe a significant relationship between HER2 gene amplification (as measured by 
FISH) and response to doxorubicin although, numerically, the absolute response rate for HER2 amplified tumors was higher than for HER2-normal tumors (28\% vs. $16 \%$ ).

The association between HER2 status and sensitivity to doxorubicin could be related to the close topographical location of the HER2 and TOP2A genes [26]; TOP2A amplification almost always occurs within the context of simultaneous HER2 amplification.

The correlation between TOP2A gene status/topo2a protein expression and response to anthracyclines has been addressed by a legion of studies [23,26,30,35-47] and are currently a matter of considerable debate. Most studies were essentially retrospective, and included breast cancer patients treated with anthracycline combinations rather than single agent anthracycline and, therefore, the activity of the other drugs of the combination could obscure any existing relationship. Finally, many of the studies were too underpowered to show clinically relevant relationships. A prospective, single arm neoadjuvant study, the TOP trial [48] has addressed the factors predictive of anti-tumor efficacy of epirubicin $\left(100 \mathrm{mg} / \mathrm{m}^{2}\right.$ every 2 or 3 weeks) in 149 breast cancer patients carrying exclusively $\mathrm{ER}^{-}$tumors. TOP2A copy number alterations were highly predictive of $p C R(p=0.0002)$. However, the target of doxorubicin is the topo2a protein rather than the gene, and there is a lack of correlation between gene status and protein expression [39,49,50], probably because of a posttranscriptional regulation of the topo2a protein. As with the TOP2A gene status, the results of the trials that evaluated the correlation of topo2a protein expression and the response to anthracyclines are contradictory, but these studies presented the same methodological caveats previously mentioned [51-53]. In our study, we found that the overexpression of topo2a protein was the stronger predictor of resistance to doxorubicin in a multivariate analyses. Further, this relationship was specific for doxorubicin, as shown by the significant topo2a protein expression-treatment interaction found in the multivariate analysis in which the whole study sample was included. The value of our findings is strengthened by the prospective and planned nature of the study, as well as the study design (comparative, single drug arms). In our study, an excess of the target enzyme/protein is detrimental in the anti-tumor activity of doxorubicin. As Esteva and Hortobagyi [35] have highlighted in an Editorial discussing the relationship of topo2a and anthracycline responsiveness, increased concentration of the target enzyme does predict reduced activity of other anti-tumor drugs (methotrexate, for example); this explanation fits well with our model.

With respect to docetaxel, a number of single genes or gene products have been proposed as predictors of response (ER, tau protein, class I, II or III $\beta$-tubulin, bcl-2, ki-67, p53, among others) [54,55]. As in the case of doxorubicin, most published studies contain significant weaknesses (retrospective and unplanned nature, and small sample size) and therefore, the real predictive values of HER2 [56,57], microtubule associated parameters [58-60], and ki- 
67 [61,62], remain undefined. In our study, ER status was a strong predictor of docetaxel activity, while the remaining markers (PR, HER2, TOP2A gene alterations or topo2a protein expression, tau protein, p27, Ki67) were not.

The ability of single genes or single gene products to predict response to cytotoxic drugs is likely a limited approach. This is not surprising since these agents do not have a single target. Anthracyclines, for instance, have many mechanisms of action other than topo2A inhibition (such as intercalation into DNA leading to inhibited synthesis of macromolecules, generation of free radicals, DNA binding and alkylation, DNA cross-linking, etc) [63]. Multiple gene models might predict response to these agents more accurately than single gene predictors.

The intrinsic subtype classification, an approach that integrates multiple individual biomarkers together to identify biologically based groups, have previously shown to exhibit prognostic value $[14,15,19]$; besides, it could be useful in predicting response to chemotherapy. A retrospective subtype analysis of patients from the Canadian MA5 study suggested that CEF is better than CMF in patients with HER-2 overexpressing tumors, but worse than CMF in the basal-like subtype; CEF and CMF were similar in ER-positive, HER-2 negative luminal subtypes [64]. In the BCIRG 001 adjuvant study, an improved 3-year DFS with TAC versus FAC treatment schemes was shown in the luminal $B$ group $(p=0.025)$, with a marginal trend in the triple negatives $(p=0.051)$ and HER2 $(p=0.068)$ subtypes. No DFS advantage was seen in the luminal A population [22]. Similarly, the GEICAM 9906 trial comparing FEC to FEC followed by weekly paclitaxel, found that the paclitaxel benefit was mainly concentrated in the triple negative/basal-like patient population [65]. However, all these studies have the disadvantage of having compared multi-drug regimens and, as such, attributing benefit to any of drug individually becomes very difficult. Our study comparing head-to-head single agent doxorubicin with single agent docetaxel showed a significant difference between doxorubicin and docetaxel: in the triple negative/basal-like tumors, doxorubicin was associated with a lower response rate and higher RCB score relative to docetaxel. Indeed, the triple negative status, as defined by IHC/FISH, was the only independent predictor of resistance (poor PathResp) to doxorubicin in a logistic regression analysis. The claudin-low subtype showed some sensitivity to chemotherapy. Both doxorubicin and docetaxel induced good pathological responses in $20-27 \%$ of patients. In our study, $40 \%$ of tumors classified as claudin-low expressed the triple negative phenotype while $44 \%$ were ER-positive, her-2- negative. The claudin-low subtype seems to be related to the mammary epithelial stem cell (21) and was initially considered to be resistant to chemotherapy (66). A recent study, however, has challenged this concept (67). 
In summary, this prospective study has shown that, although doxorubicin and docetaxel are similarly effective overall as neoadjuvant therapy of breast cancer, docetaxel does seem to be more effective than doxorubicin in the triple negative/basal-like subtype of patients. Triple negative breast tumors currently are one of the biggest challenges in the breast cancer clinic. A new class of drugs, the inhibitors of poly(ADP-ribose) polymerase-1 (PARP-1), an enzyme involved in DNA repair, could open a window of hope. PARP-1 expression is often increased in triple negative tumors. Several PARP-1 inhibitors are currently under development for use in combination with chemotherapy in triple negative breast cancer; the optimum chemotherapy regimen for the combination remains to be established. Preclinical data suggests that DNA damaging agents (i.e. platinum salts) are the best partners for PARP-1 inhibitors, however, our results may also suggest that adding a taxane to PARP-1 inhibitors and platinum salts could be beneficial to basal-like/triple negative patients. 
Appendix 1

Consort Diagram

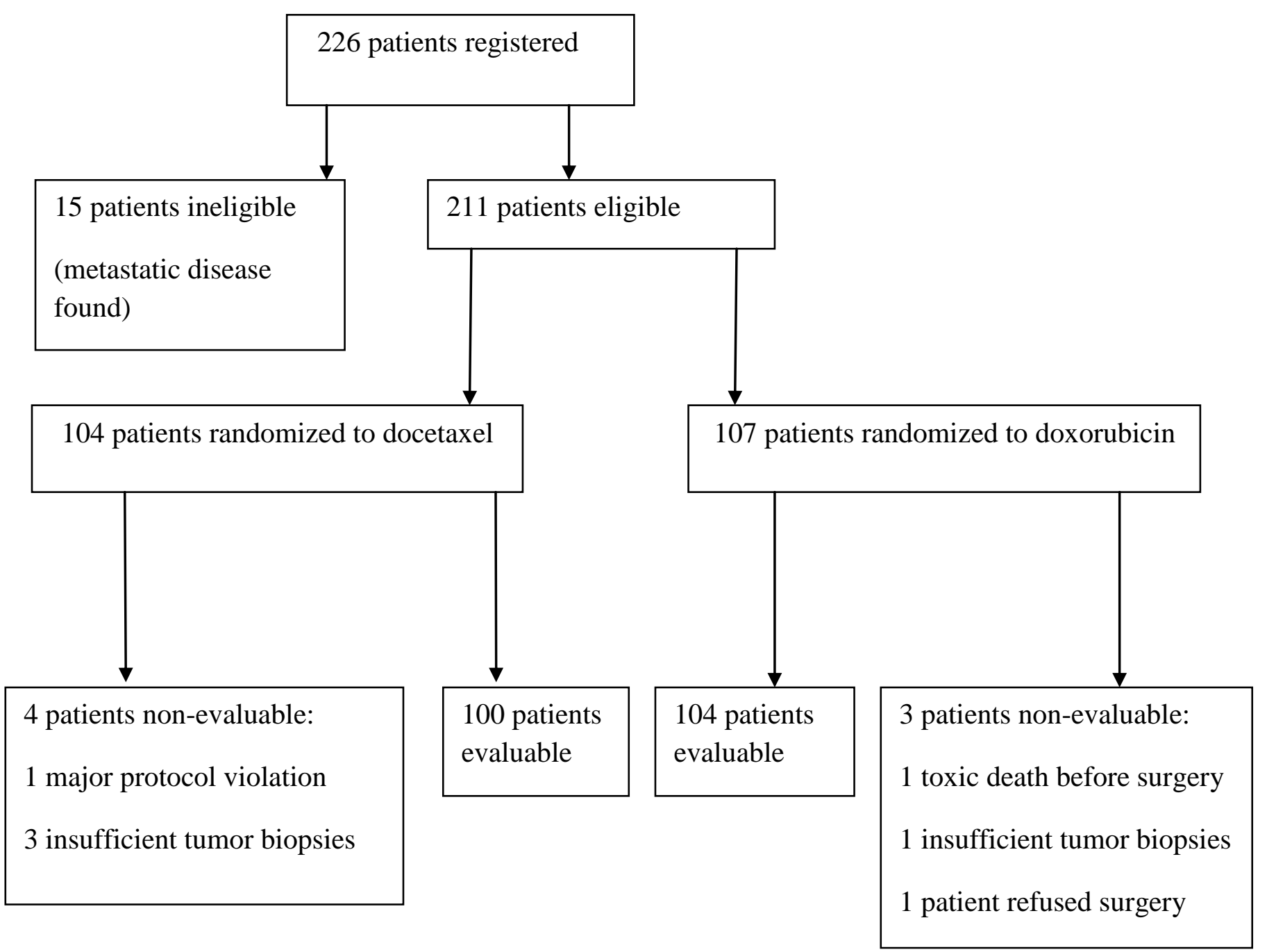


Table 1. Characteristics of the evaluable patients

\begin{tabular}{|c|c|c|c|}
\hline \multicolumn{2}{|l|}{ Variable } & \multirow{2}{*}{$\begin{array}{c}\text { Doxorubicin } \\
\mathrm{N}\end{array}$} & \multirow{2}{*}{$\begin{array}{c}\text { Docetaxel } \\
\mathrm{N}\end{array}$} \\
\hline & & & \\
\hline Number of evaluable patients & & 104 & 100 \\
\hline Median age; years (range) & & $52(26-79)$ & $51(27-77)$ \\
\hline \multicolumn{4}{|l|}{ Tumor size; $\mathrm{cm}$} \\
\hline & Median (range) & $6(2-15)$ & $6(2-15)$ \\
\hline Patients with tumors $>5 \mathrm{~cm}$ & & 60 & 55 \\
\hline \multicolumn{4}{|l|}{ Histology type } \\
\hline & Ductal & 83 & 78 \\
\hline & Lobular & 18 & 16 \\
\hline & Others & 3 & 6 \\
\hline \multicolumn{4}{|l|}{ UICC stage } \\
\hline & II & 37 & 37 \\
\hline & IIIA & 35 & 31 \\
\hline & IIIB & 32 & 33 \\
\hline \multicolumn{4}{|l|}{ Tumor grade } \\
\hline & 3 & 39 & 37 \\
\hline & $1-2$ & 65 & 63 \\
\hline
\end{tabular}


Table 2. Prediction of good PathResp (PCR+class I): Univariate analysis by treatment arm

\begin{tabular}{|c|c|c|c|c|}
\hline & DOXORUBICIN & & DOCETAXEL & \\
\hline VARIABLE & $\begin{array}{l}\text { Number of patients with } \\
\text { good pathological response/ } \\
\text { Number of determinations (\%) }\end{array}$ & $P$ & $\begin{array}{l}\text { Number of patients with } \\
\text { good pathological response/ } \\
\text { Number of determinations (\%) }\end{array}$ & $P$ \\
\hline $\begin{array}{l}\text { ER negative } \\
\text { ER positive }\end{array}$ & $\begin{array}{l}9 / 33(27 \%) \\
11 / 71(15 \%)\end{array}$ & 0.156 & $\begin{array}{l}16 / 48(33 \%) \\
4 / 52(8 \%)\end{array}$ & 0.002 \\
\hline $\begin{array}{l}\text { PR negative } \\
\text { PR positive }\end{array}$ & $\begin{array}{l}11 / 44(25 \%) \\
9 / 60(15 \%)\end{array}$ & 0.201 & $\begin{array}{l}14 / 53(26 \%) \\
6 / 47(13 \%)\end{array}$ & 0.089 \\
\hline $\begin{array}{l}\text { HER2 positive } \\
\text { HER2 negative }\end{array}$ & $\begin{array}{l}8 / 29(28 \%) \\
12 / 75(16 \%)\end{array}$ & 0.179 & $\begin{array}{l}7 / 26(27 \%) \\
13 / 74(18 \%)\end{array}$ & 0.305 \\
\hline $\begin{array}{l}\text { Topo Il } \alpha \text { IHC high } \\
\text { Topo II } \alpha \text { IHC normal }\end{array}$ & $\begin{array}{l}2 / 33(6 \%) \\
17 / 64(27 \%)\end{array}$ & 0.016 & $\begin{array}{l}4 / 26(15 \%) \\
13 / 64(20 \%)\end{array}$ & 0.769 \\
\hline $\begin{array}{l}\text { Topo Il } \alpha \text { FISH normal } \\
\text { Topo Il } \alpha \text { FISH abnormal }\end{array}$ & $\begin{array}{l}16 / 64(25 \%) \\
3 / 20(15 \%)\end{array}$ & 0.541 & $\begin{array}{l}16 / 69(23 \%) \\
1 / 12(8 \%)\end{array}$ & 0.444 \\
\hline $\begin{array}{l}\text { Topo Il } \alpha \text { FISH amplified } \\
\text { Topo Il } \alpha \text { FISH normal }\end{array}$ & $\begin{array}{l}3 / 20(15 \%) \\
16 / 64(25 \%)\end{array}$ & 0.749 & $\begin{array}{l}0 / 8(0 \%) \\
16 / 69(23 \%)\end{array}$ & 0.193 \\
\hline $\begin{array}{l}\text { BCL-2 negative } \\
\text { BCL-2 positive }\end{array}$ & $\begin{array}{l}8 / 34(23 \%) \\
8 / 61(13 \%)\end{array}$ & 0.194 & $\begin{array}{l}7 / 43(16 \%) \\
10 / 49(20 \%)\end{array}$ & 0.611 \\
\hline $\begin{array}{l}\text { TAU negative } \\
\text { TAU positive }\end{array}$ & $\begin{array}{l}10 / 47(21 \%) \\
9 / 49(18 \%)\end{array}$ & 0.721 & $\begin{array}{l}9 / 49(18 \%) \\
8 / 43(19 \%)\end{array}$ & 0.977 \\
\hline P27 negative & $7 / 33(21 \%)$ & 0.643 & $4 / 26(15 \%)$ & 0.772 \\
\hline
\end{tabular}




\begin{tabular}{|c|c|c|c|c|}
\hline P27 positive & $12 / 69(17 \%)$ & & $14 / 70(20 \%)$ & \\
\hline KI67 low & $4 / 27(15 \%)$ & 0.582 & $3 / 31(10 \%)$ & 0.108 \\
\hline KI67 high & $16 / 77(21 \%)$ & & $17 / 69(25 \%)$ & \\
\hline EGFR positive & $4 / 24(17 \%)$ & 1 & $4 / 28(14 \%)$ & 0.570 \\
\hline EGFR negative & $14 / 73(19 \%)$ & & $13 / 63(21 \%)$ & \\
\hline Cytokeratin $5 / 6$ positive & $4 / 31(13 \%)$ & 0.412 & $4 / 23(17 \%)$ & 1 \\
\hline Cytokeratin $5 / 6$ negative & $14 / 67(21 \%)$ & & $14 / 67(21 \%)$ & \\
\hline Tumor size $>5 \mathrm{~cm}$ & $11 / 60(18 \%)$ & 0.786 & $3 / 55(5 \%)$ & $<0.0001$ \\
\hline Tumor size $\leq 5 \mathrm{~cm}$ & $9 / 44(20 \%)$ & & $17 / 45(38 \%)$ & \\
\hline Stage II & $9 / 37(24 \%)$ & 0.611 & 14/37(38\%) & 0.002 \\
\hline Stage IIIA & $6 / 35(17 \%)$ & & $4 / 30(13 \%)$ & \\
\hline Stage IIIB & $5 / 32(16 \%)$ & & $2 / 33(6 \%)$ & \\
\hline Grade 3 & $7 / 39(18 \%)$ & 0.797 & $9 / 38(24 \%)$ & 0.471 \\
\hline Grade $1+2$ & $13 / 65(20 \%)$ & & $11 / 62(18 \%)$ & \\
\hline Ductal & $17 / 83(20 \%) 3 / 17(18 \%)$ & & $16 / 78(20 \%)$ & 0.537 \\
\hline Lobular & $0 / 4(0 \%)$ & 0.588 & $2 / 16(12 \%)$ & \\
\hline Others & & & $2 / 6(33 \%)$ & \\
\hline
\end{tabular}


Table $3 e$ (on line only)

Multivariate analysis: factors predictive of good PathRes (PCR+class I) in the whole sample

\begin{tabular}{|l|l|l|l|}
\hline Variable & $\begin{array}{l}\text { Odds } \\
\text { Ratio }\end{array}$ & $95 \% \mathrm{Cl}$ & P value \\
\hline Topisomerase Il $\alpha$ expression & 12.46 & $2.36-65.62$ & 0.003 \\
\hline ER & 5.03 & $2.06-12.28$ & $<0.0001$ \\
\hline T size & 3.11 & $1.38-7.0$ & 0.006 \\
\hline Topisomerase Il $\alpha$ expression/treatment interaction & 0.12 & $0.01-0.97$ & 0.048 \\
\hline
\end{tabular}

The factors predictive of good Path Res in the overall population are low topo lla expression, ER-negativity, smaller T size. A significant interaction between Topisomerase lla expression and treatment was also found. 
Table 4e. Prediction of poor PathResp (class III): Univariate analysis by treatment arm (on line only)

\begin{tabular}{|c|c|c|c|c|}
\hline & DOXORUBICIN & & DOCETAXEL & \\
\hline VARIABLE & $\begin{array}{l}\text { Number of patients with } \\
\text { poor pathological response/ } \\
\text { Number of determinations (\%) }\end{array}$ & $P$ & $\begin{array}{l}\text { Number of patients with } \\
\text { poor pathological response/ } \\
\text { Number of determinations (\%) }\end{array}$ & $P$ \\
\hline ER negative & $17 / 33(51 \%)$ & 0.314 & $34 / 48$ (71\%) & 0.560 \\
\hline ER positive & $44 / 71(62 \%)$ & & $34 / 52(65 \%)$ & \\
\hline $\begin{array}{l}\text { PR negative } \\
\text { PR positive }\end{array}$ & $\begin{array}{l}22 / 44(50 \%) \\
39 / 60(65 \%)\end{array}$ & 0.125 & $\begin{array}{l}37 / 53(70 \%) \\
31 / 47(66 \%)\end{array}$ & 0.680 \\
\hline $\begin{array}{l}\text { HER2 positive } \\
\text { HER2 negative }\end{array}$ & $\begin{array}{l}43 / 75(57 \%) \\
18 / 29(62 \%)\end{array}$ & 0.660 & $\begin{array}{l}48 / 74(65 \%) \\
20 / 26(77 \%)\end{array}$ & 0.257 \\
\hline $\begin{array}{l}\text { Topo Il } \alpha \text { IHC high } \\
\text { Topo II } \alpha \text { IHC normal }\end{array}$ & $\begin{array}{l}40 / 64(62 \%) \\
20 / 33(61 \%)\end{array}$ & 0.856 & $\begin{array}{l}4 / 64(69 \%) \\
17 / 26(65 \%)\end{array}$ & 0.757 \\
\hline $\begin{array}{l}\text { Topo Il } \alpha \text { FISH normal } \\
\text { Topo Il } \alpha \text { FISH abnormal }\end{array}$ & $\begin{array}{l}12 / 20(60 \%) \\
42 / 64(66 \%)\end{array}$ & 0.647 & $\begin{array}{l}7 / 12(58 \%) \\
48 / 69(70 \%)\end{array}$ & 0.442 \\
\hline $\begin{array}{l}\text { BCL-2 negative } \\
\text { BCL-2 positive }\end{array}$ & $\begin{array}{l}21 / 34(62 \%) \\
35 / 61(57 \%)\end{array}$ & 0.677 & $\begin{array}{l}28 / 43(65 \%) \\
34 / 49(69 \%)\end{array}$ & 0.663 \\
\hline $\begin{array}{l}\text { Tau negative } \\
\text { Tau positive }\end{array}$ & $\begin{array}{l}28 / 47(60 \%) \\
30 / 49(61 \%)\end{array}$ & 0.869 & $\begin{array}{l}29 / 49(60 \%) \\
32 / 43(74 \%)\end{array}$ & 0.123 \\
\hline P27 negative & $19 / 33(58 \%)$ & 0.970 & $14 / 26(54 \%)$ & 0.077 \\
\hline
\end{tabular}




\begin{tabular}{|c|c|c|c|c|}
\hline P27 positive & $40 / 69(58 \%)$ & & $51 / 70(73 \%)$ & \\
\hline KI67 low & $16 / 27(60 \%)$ & 0.941 & $19 / 31(61 \%)$ & 0.335 \\
\hline KI67 high & $45 / 77(58 \%)$ & & $49 / 69$ (71\%) & \\
\hline EGFR positive & $47 / 73(64 \%)$ & 0.108 & $44 / 63(70 \%)$ & 0.600 \\
\hline EGFR negative & $11 / 24(46 \%)$ & & $18 / 28(64 \%)$ & \\
\hline Cytokeratin $5 / 6$ positive (OK) & $42 / 67(63 \%)$ & 0.460 & $47 / 67(70 \%)$ & 0.958 \\
\hline Cytokeratin 5/6 negative & $17 / 31(55 \%)$ & & $16 / 23(70 \%)$ & \\
\hline Tumor size $>5 \mathrm{~cm}$ & $27 / 44(61 \%)$ & 0.631 & $36 / 45(80 \%)$ & 0.020 \\
\hline Tumor size $\leq 5 \mathrm{~cm}$ & $34 / 60(57 \%)$ & & $32 / 55(58 \%)$ & \\
\hline Stage II & $26 / 37(70 \%)$ & 0.200 & $33 / 37(89 \%)$ & 0.001 \\
\hline Stage IIIA & $18 / 35(51 \%)$ & & $19 / 30(63 \%)$ & \\
\hline Stage IIIB & $17 / 32(53 \%)$ & & $16 / 33(48 \%)$ & \\
\hline Grade 3 & $40 / 65(61 \%)$ & 0.441 & $43 / 62(70 \%)$ & 0.607 \\
\hline Grade $1+2$ & $21 / 39(54 \%)$ & & $25 / 38(66 \%)$ & 0.826 \\
\hline Ductal & $44 / 83(53 \%)$ & & $53 / 78(68 \%)$ & 0.534 \\
\hline Lobular & $14 / 17(82 \%)$ & 0.065 & $12 / 16(75 \%)$ & \\
\hline Others & $3 / 4$ (75\%) & & $3 / 6(50 \%)$ & \\
\hline
\end{tabular}


Table 4. Anti-tumor activity of doxorubicin and docetaxel in intrinsic subtypes based on IHC/FISH

\begin{tabular}{|c|c|c|c|c|c|c|c|c|c|}
\hline & \multicolumn{3}{|c|}{ Good PathRes (pCR+class I) } & \multicolumn{3}{|c|}{ Poor PathRes (class III) } & \multicolumn{3}{|c|}{$\begin{array}{l}\text { Residual Cancer Burden } \\
\qquad(\text { mean } \pm \text { SEM) }\end{array}$} \\
\hline & doxorubicin & docetaxel & $\begin{array}{c}P \\
\text { value }\end{array}$ & doxorubicin & docetaxel & $\begin{array}{c}P \\
\text { value }\end{array}$ & doxorubicin & docetaxel & $\begin{array}{c}P \\
\text { value }\end{array}$ \\
\hline $\begin{array}{c}\text { Luminal } \\
\text { A }\end{array}$ & $3 / 18(17 \%)$ & $\begin{array}{c}2 / 18 \\
(11 \%)\end{array}$ & 1.000 & $7 / 18(39 \%)$ & $\begin{array}{c}7 / 18 \\
(39 \%)\end{array}$ & 1.000 & $2.622 \pm 0.3667$ & $2.572 \pm 0.2915$ & 0.680 \\
\hline $\begin{array}{l}\text { Luminal } \\
\text { B }\end{array}$ & $9 / 55(16 \%)$ & $\begin{array}{c}6 / 42 \\
(14 \%)\end{array}$ & 0.779 & $20 / 55(36 \%)$ & $\begin{array}{l}13 / 42 \\
(31 \%)\end{array}$ & 0.709 & $2.593 \pm 0.1776$ & $2.621 \pm 0.1689$ & 0.878 \\
\hline Her2 & $6 / 11(55 \%)$ & $\begin{array}{c}4 / 12 \\
(33 \%)\end{array}$ & 0.414 & $2 / 11(18 \%)$ & $\begin{array}{c}3 / 12 \\
(27 \%)\end{array}$ & 1.000 & $1.809 \pm 0.477$ & $2.075 \pm 0.3568$ & 0.557 \\
\hline Triple- & $2 / 20(10 \%)$ & $8 / 28$ & 0.160 & $14 / 20(70 \%)$ & $9 / 28$ & 0,010 & $3.255 \pm 0.3291$ & $2.232 \pm 0.2913$ & 0.030 \\
\hline
\end{tabular}




\begin{tabular}{|c|c|c|c|c|c|c|c|c|c|}
\hline & \multicolumn{3}{|c|}{ Good PathRes (pCR+class I) } & \multicolumn{3}{|c|}{ Poor PathRes (class III) } & \multicolumn{3}{|c|}{$\begin{array}{c}\text { Residual Cancer Burden } \\
\text { (mean } \pm \text { SEM) }\end{array}$} \\
\hline & doxorubicin & docetaxel & $\begin{array}{c}P \\
\text { value }\end{array}$ & doxorubicin & docetaxel & $\begin{array}{c}\mathbf{P} \\
\text { value }\end{array}$ & doxorubicin & docetaxel & $\begin{array}{c}P \\
\text { value }\end{array}$ \\
\hline $\begin{array}{c}\text { Luminal } \\
\text { A }\end{array}$ & $1 / 12(8 \%)$ & $0 / 5(0 \%)$ & NS & $8 / 1267 \%$ & $2 / 540 \%$ & 0.593 & $3.386 \pm 0.343$ & $2.839 \pm 0.345$ & NS \\
\hline
\end{tabular}

Table 5: Anti-tumor activity of doxorubicin and docetaxel in intrinsic subtypes based on Agilent cDNA microarrays 


\begin{tabular}{|c|l|l|l|l|l|l|l|l|l|}
\hline $\begin{array}{c}\text { Luminal } \\
\text { B }\end{array}$ & $2 / 13(15 \%)$ & $0 / 11(0 \%)$ & NS & $2 / 1315 \%$ & $4 / 11$ & 0.357 & $2.220 \pm 0.334$ & $2.806 \pm 0.274$ & NS \\
\hline $\begin{array}{c}\text { Her2- } \\
\text { enriched }\end{array}$ & $1 / 6(17 \%)$ & $2 / 5(40 \%)$ & NS & $4 / 667 \%$ & $1 / 520 \%$ & 0.242 & $\begin{array}{l}3.088 \pm \\
0.674\end{array}$ & $1.670 \pm 0.792$ & NS \\
\hline $\begin{array}{c}\text { Basal- } \\
\text { like }\end{array}$ & $0 / 8(0 \%)$ & $5 / 9(56 \%)$ & 0.029 & $5 / 8(62 \%)$ & $2 / 922 \%$ & 0.153 & $3.245 \pm 0.483$ & $1.626 \pm 0.499$ & 0.039 \\
\hline $\begin{array}{c}\text { Claudin- } \\
\text { low }\end{array}$ & $3 / 11(27 \%)$ & $1 / 5(20 \%)$ & NS & $6 / 11(54 \%)$ & $2 / 540 \%$ & 1 & $2.626 \pm$ & $2.538 \pm 0.728$ & NS \\
\hline \begin{tabular}{c} 
Normal \\
\hline
\end{tabular} & $1 / 4(25 \%)$ & $2 / 5(40 \%)$ & NS & $1 / 425 \%$ & $3 / 560 \%$ & 0.524 & $2.183 \pm 0.766$ & $2.821 \pm 0.639$ & NS \\
\hline
\end{tabular}


Figure 1. Correlation between topo2a expression and response to doxorubicin and docetaxel. The differences among categories are statistically significant in the case of doxorubicin $(p=0.017)$ but not in the case of docetaxel $(p=0.778$; Pearson chi-squared test $)$

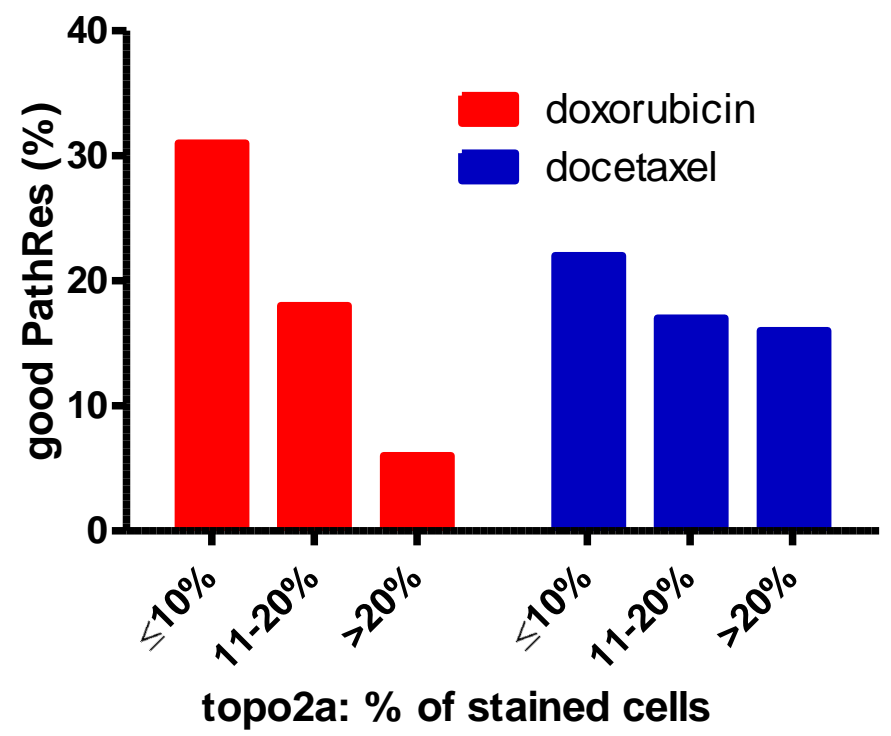

Figure 2: Correlation between topo2a protein expression and intrinsic subtype

topolla protein low

topolla protein high

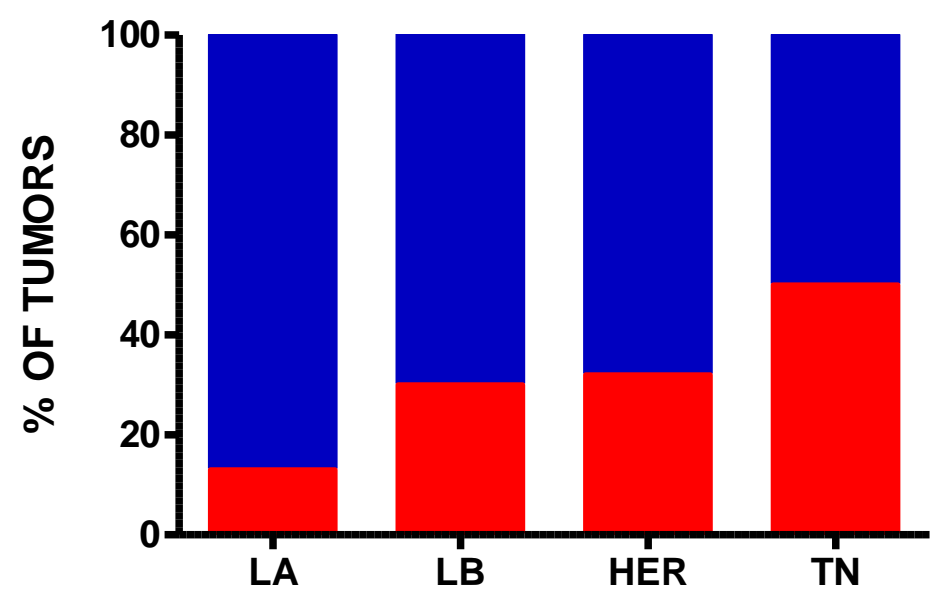

INTRINSIC SUBTYPE (IHC/FISH) 


\section{REFERENCES}

1. Polychemotherapy for early breast cancer: an overview of the randomised trials. Early Breast Cancer Trialists' Collaborative Group. Lancet 1998;352(9132):930-42.

2. Effects of chemotherapy and hormonal therapy for early breast cancer on recurrence and 15-year survival: an overview of the randomised trials. Lancet 2005;365(9472):1687717 .

3. Henderson IC, Berry DA, Demetri GD, et al. Improved outcomes from adding sequential paclitaxel but not from escalating doxorubicin dose in an adjuvant chemotherapy regimen for patients with node-positive primary breast cancer. J Clin Oncol 2003;21:976-83.

4. Mamounas EP, Bryant J, Lembersky BC, et al. Paclitaxel after doxorubicin plus cyclophosphamide as adjuvant chemotherapy for nodepositive breast cancer: results from NSABP-B 28. J Clin Oncol 2005;23:3686-96.

5. Martin M, Pienkowski T, Mackey J, et al. Adjuvant docetaxel for node positive breast cancer. N Engl J Med 2005;352:2302-13.

6. Roche H, Fumoleau P, Spielmann M, et al. Sequential adjuvant epirubicin-based and docetaxel chemotherapy for node-positive breast cancer patients: The FNCLCC PASC 01 Trial. J Clin Oncol 2006;24:5664-71.

7. Jones S, Holmes FA, O’Shaughnessy JO et al. Docetaxel with cyclophosphamide is associated with an overall survival benefit compared with doxorubicin and cyclophosphamide: 7-year follow-up of US Oncology Research Trial 9735. J Clin Oncol 2009;27:1177-83.

8. Martin M, Rodriguez-Lescure A, Ruiz A, et al. Randomized phase 3 trial of fluorouracil, epirubicin, and cyclophosphamide alone or followed by paclitaxel for early breast cancer. J Natl Cancer Inst 2008;100:805-14.

9. Francis P, Crown J, Di Leo A, et al. Adjuvant chemotherapy with sequential or concurrent anthracycline and docetaxel: Breast International Group 02-98 randomized trial. J Natl Cancer Inst 2008;100(2):121-33.

10. Gianni L, Baselga J, Eiermann W. Phase III trial valuating the addition of paclitaxel to doxorubicin followed by cyclophosphamide, methotrexate, and fluorouracil as adjuvant or primary systemic therapy: European Cooperative Trial in Operable Breast Cancer. J Clin Oncol 2009;27:2474-81. 
11. Goldstein LJ, O'Neill A, Sparano JA, et al. Concurrent doxorubicin plus docetaxel is not more effective than concurrent doxorubicin plus cyclophosphamide in operable breast cancer with 0 to 3 positive axillary nodes: North American Breast Cancer Intergroup Trial E 2197. J Clin Oncol 2008;26:4078-85.

12. Ellis $P$, Barrett-Lee $P$, Johnson L, et al. Sequential docetaxel as adjuvant chemotherapy for early breast cancer (TACT): an open-label, phase III, randomised controlled trial. Lancet 2009;373:1681-92.

13. Perou CM, Sorlie T, Eisen MB, et al. Molecular portraits of human breast tumours. Nature 2000;406:747-52.

14. Sorlie T, Perou CM, Tibshirani R, et al. Gene expression patterns of breast carcinomas distinguish tumor subclasses with clinical implications. Proc Natl Acad Sci USA 2001;98:10869-74.

15. Sorlie T, Tibshirani R, Parker J, et al. Repeated observation of breast tumor subtypes in independent gene expression data sets. Proc Natl Acad Sci USA 2003;100:8418-23. 16. Cheang MA, Chia SK, Vodue D, et al. Ki67 index, HERT2 status, and prognosis of patients with luminal B breast cancer. J Natl Cancer Inst 2009;101:736-50.

17. Carey L, Dees EC, Sawyer L, et al. The triple negative paradox: primary tumor chemosensitivity of breast cancer subtypes. Clin Cancer Res 2007;13:2329-34.

18. Rouzier R, Perou CM, Symmans WF, et al. Breast cancer molecular subtypes respond differently to preoperative chemotherapy. Clin Cancer Res 2005;11:5678-85.

19. Symmans WF, Peintinger F, Hatzis C, Rajan R, Kuerer H, Valero V. Measurement of residual breast cancer burden to predict survival after neoadjuvant chemotherapy. J Clin Oncol 2007;25:4414-22.

20. Parker JS, Mullins M, Cheang MC, et al. Supervised risk predictor of breast cancer based on intrinsic subtypes. J Clin Oncol 2009;27:1160-7.

21. Prat A, Parker J, Karginova O, et al. Phenotyphic and molecular characterization of the claudin-low intrinsic subtype of breast cancer. Breast Cancer Res, 2010; 12: R68. 22. Hugh J, Hanson J, Cheang MCU, et al: Breast cancer subtypes and response to docetaxel in node-positive breast cancer: Use of an immunohistochemical definition in the BCIRG 001 Trial. J Clin Oncol 2009;27:1168-76.

23. Arriola E, Moreno A, Varela M, et al. Predictive value of HER-2 and topoisomerase II $\alpha$ in response to primary doxorubicin in breast cancer. Eur J Cancer 2006;42:2954-60. 
24. Tham YL, Gomez LF, Mohsin S, et al. Clinical response to neoadjuvant docetaxel predicts improved outcome in patients with large locally advanced breast cancer. Breast Cancer Res Treat 2005;94:279-84.

25. Gradishar WJ, Wedam SB, Jahanzeb M, et al. Neoadjuvant docetaxel followed by adjuvant doxorubicin and cyclophosphamide in patients with stage III breast cancer. Ann Oncol 2005; 16:1297-304.

26. Slamon DJ, Press MF. Alterations in the TOP2A and HER2 genes: association with adjuvant anthracycline sensitivity in human breast cancers. J Natl Cancer Inst 2009;101: 615-9.

27. Pritchard KI, Shepherd LE, O'Malley FP, et al. HER2 and responsiveness of breast cancer to adjuvant chemotherapy. N Engl J Med 2006;354:2103-11.

28. Gennari A, Sormani MP, Pronzato P, et al. HER2 status and efficacy of adjuvant anthracyclines in early breast cancer: a pooled analysis of randomized trials. J Natl Cancer Inst 2008;100:14-20.

29. Zhang F, Yang Y, Smith T, et al. Correlation between HER-2 expression and response to neoadjuvant chemotherapy with 5-fluororuacil, doxorubicin, and cyclophosphamide in patients with breast carcinoma. Cancer 2003;97:1758-65.

30. Penault-Llorca F, Cayre A, Bouchet Mishellany F, et al. Induction chemotherapy for breast carcinoma: predictive markers and relation with outcome. Int J Oncol 2003;22:1319-25.

31. Petit T, Wilt M, Velten M, et al. Comparative value of tumour grade, hormonal receptors, Ki-67, HER-2 and topoisomerase II alpha status as predictive markers in breast cancer patients treated with neoadjuvant anthracycline-based chemotherapy. Eur J Cancer 2004;40:205-11.

32. Geisler S, Lǿnning PE, Aas T, et al. Influence of TP53 gene alterations and c-erbB2 expression on the response to treatment with doxorubicin in locally advanced breast cancer. Cancer Res 2001;61:2505-12.

33. Di Leo A, Chan S, Paesmans M, et al. HE2/neu as a predictive marker in a population of advanced breast cancer patients randomly treated either with single-agent doxorubicin or single-agent docetaxel. Breast Cancer Res Treat 2004;86:197-206.

34. Järvinen TAH, Holli K, Isola JJ. Predictive value of topoisomerase II $\alpha$ and other prognostic factors for epirubicin chemotherapy in advanced breast cancer. Br J Cancer 1998;77:2267-73. 
35. Esteva F, Hortobagyi GN. Topoisomerase II $\alpha$ amplification and anthracycline-based chemotherapy: The jury is still out. J Clin Oncol 2009;27:3416-7.

36. Pritchard KI. Are HER2 and TOP2A useful as prognostic or predictive biomarkers for anthracycline-based adjuvant chemotherapy for breast cancer? J Clin Oncol 2009;27:3875-6.

37. Gianni L, Valagussa P. Anthracyclines and early breast cancer: The end of an era? J Clin Oncol 2009;27:1155-7.

38. Buzdar AU. Topoisomerase II $\alpha$ gene amplification and response to anthracyclinecontaining adjuvant chemotherapy in breast cancer. J Clin Oncol 2006;24:2409-11. 39. Coon JS, Marcus E, Gupta-Burt S, et al. Amplification and overexpression of topoisomerase II $\alpha$ predict response to anthracycline-based therapy in locally advanced breast cancer. Clin Cancer Res 2002;8:1061-7.

40. Cardoso F, Durbecq V, Larsimont D, et al. Correlation between complete response to anthracycline-based chemotherapy and topoisomerase II $\alpha$ gene amplification and protein expression in locally advanced breast cancer. Int J Oncol 2004;24:201-9.

41. Knoop AS, Knudsen H, Basley E, et al. Retrospective analysis of topoisomerase IIa amplifications and deletions as predictive marker in primary breast cancer patients randomly assigned to cyclophosphamide, methotrexate, and fluorouracil or cyclophosphamide, epirubicin and fluorouracil: Danish Breast Cancer Cooperative Group. J Clin Oncol 2005;23:7483-90.

42. Tanner M, Isola J, Wiklund T, et al. Topoisomerase II-alpha gene amplification predicts favourable treatment response to tailored and dose-escalated anthracycline-based adjuvant chemotherapy in HER-2/neu-amplified breast cancer: Scandinavian Breast Group Trial 9401. J Clin Oncol 2006;24:2428-36.

43. Di Leo A, Gancberg D, Larsimont D, et al. HER-2 amplification and topoisomerase II $\alpha$ gene aberrations as predictive markers in node-positive breast cancer patients randomly treated either with an anthracycline-based therapy or with cyclophosphamide, methotrexate, and 5-fluorouracil. Clin Cancer Res 2002;8:1107-16.

44. Park K, Kim J, Lim S, Han S. Topoisomerase II- $\alpha$ (topoII) and HER2 amplification in breast cancers and response to preoperative doxorubicin chemotherapy. Eur J Cancer 2003;39:631-4.

45. Tubbs R, Barlow WE, Budd T, et al. Outcome of patients with early-stage breast cancer treated with doxorubicin-based adjuvant chemotherapy as a function of HER2 and TOP2A status. J Clin oncol 2009;27:3881-6. 
46. O`Malley FP, Chia S, Tu D, et al. Topoisomerase II alpha and responsiveness of breast cancer to adjuvant chemotherapy. J Natl Cancer Inst 2009;101:644-50.

47. Harris LN, Broadwater G, Abu-Khalaf M, et al. Topoisomerase II $\alpha$ amplification does not predict benefit from dose-intense cyclophosphamide, doxorubicin, and fluorouracil therapy in HER-2amplified early breast cancer: Results of CALGB 8541/150013. J Clin Oncol 2009;27:3430-6.

48. Desmedt C, E. Azambuja E, Larsimont D, et al. Predicting the efficacy of anthracyclines in breast cancer (BC) patients: Results of the neoadjuvant TOP trial. J Clin Oncol 2009;27 (May 20 supplement):523 [abstr.]

49. Durbecq V, Desmedt C, Paesmans M, et al. Correlation between topoisomerase II $\alpha$ (Topo-II) gene amplification and protein expression in her-2 amplified breast cancer patients. Int J Oncol 2004;25:1473-9.

50. Mueller RE, Parkes RK, Androlis J, O`Malley FP. Amplification of the TOP2A gene does not predict high levels of topoisomerase II alpha protein in human breast tumor samples. Genes Chromosomes Cancer 2004;39:288-97.

51. Durbecq V, Paesmans M, Cardoso F, et al. Topoisomerase-II $\alpha$ expression as a predictive marker in a population of advanced breast cancer patients randomly treated either with single-agent doxorubicin or single-agent docetaxel. Molecular Cancer Ther 2004;3:1207-14.

52. Järvinen TAH, Holli K, Kuukasjärvi T, Isola JJ. Predictive value of topoisomerase II $\alpha$ and other prognostic factors for epirubicin chemotherapy in advanced breast cancer.Br $\mathbf{J}$ Cancer 1998;77:2267-73.

53. Di Leo A, Larsimont D, Gancberg D, et al. HER-2 and topo-isomerase II $\alpha$ as predictive markers in a population of node-positive breast cancer patients randomly treated with adjuvant CMF or epirubicin plus cyclophosphamide. Ann Oncol 2001;12:1081-9.

54. Noguchi S. Predictive factors for response to docetaxel in human breast cancer. Cancer Sci 2006;97:813-20.

55. Pustzai L. Markers predicting clinical benefit in breast cancer from microtubuletargeting agents. Ann Oncol 2007;18 (suppl 12): xii15-xii20.

56. Gonzalez-Angulo A, Krishnamurthy S, Broglio KR, et al. Lack of association between amplification of her- 2 and response to preoperative taxanes in patients with breast carcinoma. Cancer 2004;101:258-63. 
57. Learn PA, Yeh IT, McNutt M, et al. HER2/neu expression as predictor of response to neoadjuvant docetaxel in patients with operable breast carcinoma. Cancer 2005;103:225260 .

58. Galmarini CM, Treilleux I, Cardoso F, et al. Class III $\beta$-tubulin isotype predicts response in adjuvant breast cancer patients randomly treated either with single-agent doxorubicin or docetaxel. Clin Cancer Res 2008;14:4511-6.

59. Hasegawa S, Miyoshi Y, Egawa C, et al. Prediction of response to docetaxel by quantitative analysis of class I and III $\beta$-tubulin isotype mRNA expression in human breast cancers. Clin Cancer Res 2003;9:2992-7.

60. Bernard-Marty C, Treilleux I, Dumontet C, et al. Microtubule-associated parameters as predictive markers of docetaxel activity in advanced breast cancer patients: results of a pilot study. Clin Cancer Breast 2002;3:341-5.

61. Pernault-Llorca F, André F, Sagan C, et al. Ki67 expression and docetaxel efficacy in patients with estrogen receptor-positive breast cancer. J Clin Oncol 2009;27:2809-15.

62. Miyoshi Y, Kurosumi M, Kurebayashi J, et al. Low nuclear grade but not cell proliferation predictive of pathological complete response to docetaxel in human breast cancer. J Cancer Res Clin Oncol 2008;134:561-7.

63. Minotti G, Menna P, Salvatorelli E, et al. Anthracyclines: Molecular advances and pharmacologic developments in antitumor activity and cardiotoxicity. Pharmacol Rev 2004;56:185-229.

64. Cheang M, Chia SK, Tu D, et al. Anthracyclines in basal breast cancer: The NCICCTG trial MA5 comparing adjuvant CMF to CEF. J Clin Oncol 2009;27(May 20 suppl): 519 [abstr.]

65. Martín M, Rodríguez-Lescure A, Ruiz A, et al. Molecular predictors of efficacy of adjuvant weekly paclitaxel in early breast cancer. Breast Cancer Res Treat 2010;123:14957.

66. Fillmore CM, Kuperwasser C. Human breast cancer cell lines contain stem-like cells that self-renew, give rise to phenotypically diverse progeny and survive chemotherapy. Breast Cancer Research 2008, 10:R25.

67. Aulmann S, Waldburger N, Penzel R, Andrulis M, Schirmacher P, Sinn HP. Reduction of CD44+/CD24- breast cancer cells by conventional cytotoxic chemotherapy. Human Pathology 2010; 41: 574-581. 